\title{
O transporte público coletivo sob a lógica da produção capitalista do espaço: uma análise do serviço de ônibus na Região Metropolitana do Recife
}

Collective public transport under the logic of the capitalist production of space: an analysis of the bus service in the Metropolitan Region of Recife

Marília do Nascimento Silva [l] Tomás de Albuquerque Lapa [II]

\section{Resumo}

Nas sociedades urbanas atuais, o crescimento do papel do Estado convive com o processo de privatização dos serviços prestados por esse apareIho. A justificativa tradicional está na busca por maior competitividade e eficiência nos serviços prestados. Mesmo o Estado sendo cada vez mais indispensável na mediação entre os interesses privados e coletivos, no caso do transporte público coletivo, no contexto brasileiro, a lógica que o constituiu, enquanto serviço de "caráter essencial", o exime da responsabilidade pública que Ihe cabe, abrindo janelas para uma discussão em torno da dinâmica de gestão e de funcionamento desse equipamento. Este artigo analisa o transporte público coletivo, na Região Metropolitana do Recife, sob a lógica da produção capitalista do espaço.

Palavras-chave: transporte coletivo; produção do espaço; mobilidade periférica; arranjos institucionais; gestão metropolitana.

\begin{abstract}
In today's urban societies, the growth of the State's role coexists with the privatization process of the services provided by this apparatus. The traditional justification lies in the search for greater competitiveness and efficiency in the services provided. The State has been increasingly indispensable in the mediation between private and collective interests; however, in the case of collective public transport in the Brazilian context, the logic that constituted it as an essential service exempts it from the public responsibility that belongs to it, opening windows for a discussion about the dynamics of the management and operation of this equipment. This article analyzes collective public transport in the Metropolitan Region of Recife in the perspective of the capitalist production of space.
\end{abstract}

Keywords: collective transport; space production; peripheral mobility; institutional arrangements; metropolitan management. 


\section{Introdução}

0 presente artigo corresponde a um ensaio de revisão teórica sobre a temática do transporte público coletivo, na lógica da produção capitalista do espaço. A abordagem contempla o papel do Estado, da sociedade e do mercado, no contexto das transformações urbanas, e caminha para a discussão sobre a gestão dos serviços de ônibus na Região Metropolitana do Recife.

Ao longo do tempo, as sociedades humanas criaram e recriaram formas de organização e aperfeiçoamento de suas atividades cotidianas, transformando seu espaço de vivência no palco de construção dessas relações. Tendo em vista o processo de formação das cidades, marcado principalmente pela lógica capitalista dos novos modos de produção (Harvey, 2005), o transporte motorizado tornou-se um instrumento indispensável para a conexão de pessoas e atividades nos centros urbanos.

A necessidade de deslocamento, incentivada por uma cultura de consumo individual, possibilitou a formação de uma nova estrutura viária marcada pelo fluxo intenso de veículos particulares, causando uma série de dificuldades tanto na acessibilidade aos serviços e equipamentos urbanos quanto na mobilidade de citadinos/as. Um reflexo disso é que, nas grandes cidades brasileiras, como o Recife, deixa-se de tratar o transporte público coletivo como prioridade do planejamento urbano local, implicando o transporte de usuários/as na condição de verdadeiros enlatados, dentro dos veículos coletivos, no fluxo do trânsito urbano.

Sem alternativas aceitáveis, as estruturas viárias tornam os usuários/as, principalmente dos transportes de uso coletivo, "reféns da imobilidade urbana", tanto pelos aspectos ligados às infraestruturas viárias quanto pela dinâmica da gestão de funcionamento do serviço, que deixa sem resposta questões como a facilidade de deslocamento, o conforto durante a viagem e a segurança. No aporte desses aspectos, surgem as seguintes questões que movimentam a estrutura do trabalho: "Qual o papel do Estado na provisão de equipamentos urbanos de transporte?"; "Como a metropolização do transporte público coletivo evidencia o processo de expansão da produção capitalista urbana?"; e "Até que ponto o serviço de ônibus prestado confere à população o direito à cidade?".

0 objetivo deste artigo é analisar o fenômeno da metropolização do transporte público coletivo, sob a ótica da gestão do serviço de ônibus na Região Metropolitana do Recife, na perspectiva da produção capitalista do espaço.

\section{0 fenômeno urbano e a produção do espaço}

Diante do processo de (re)produção das atividades humanas, o transporte passou a ser um instrumento indispensável para a conexão de pessoas, equipamentos e bens de consumo entre os territórios. De acordo com Lefevbre (2006), espaço é "a inscrição do tempo no mundo", é nele que os ritmos da população definem o cotidiano, formado por uma multiplicidade de momentos, com diferentes durações: trabalho profissional, voluntário, descanso, arte, jogo, amor, luta, conhecimento, lazer, cultura... 
As formas de adaptação para suprir necessidades de sobrevivência possibilitaram o processo de formação das cidades. Iniciada no período da Revolução Industrial e intensificada, principalmente, a partir do século XX, a dinâmica de crescimento das sociedades transformou o arranjo dos modos e condições de funcionamento do trabalho, atribuindo à indústria um papel primordial na fabricação de bens e serviços, produzidos anteriormente no espaço doméstico pelos próprios membros dos núcleos familiares. De acordo com Bauman (1999), com o processo de transição dos modos de produção, as "sociedades produtoras" deram lugar às "sociedades de consumo" para possibilitar o escoamento do excedente de produção, colocando os seus membros na condição de consumidores.

A sociedade que nasce da industrialização e procede-a é denominada, por Lefebvre (1999), sociedade urbana. De acordo com o autor, o processo de transição dos modos de vida das organizações humanas é característico do fenômeno urbano e transcorre da seguinte maneira:

A não cidade (indústria) e anticidade vão conquistar a cidade, penetrá-la, fazê-la explodir, e com isso estendê-la desmesuradamente, levando à urbanização da cidade, ao tecido urbano recobrindo as remanescências da cidade anterior à indústria. (p. 25)

Nessa dimensão, o espaço urbano torna-se o lugar da troca e de encontro das coisas e das pessoas. Essa troca requer comunicação, confronto, comparação e, por conseguinte, linguagem e discurso, signos e trocas de signos, transferindo dimensões do espaço-temporal para uma realidade coberta de representações sociais (ibid.).

Segundo Secchi (2006), a cidade é resultado da construção histórica de ideias e imaginários decorrentes das atividades humanas. Não se trata de uma estrutura presa e limitada às suas formas tangenciais, mas de um conjunto de dimensões simbólicas de representações formadas ao longo do tempo, o que a caracteriza como múltipla, heterogênea e em constante transformação.

De acordo com Abramo (1995), a urbanização seria, sobretudo, o momento de transição nas características que o urbano desempenha nas relações sociais de produção e nos mecanismos necessários à sua reprodução. Para Augé (2010), a urbanização do mundo é uma característica essencial do fenômeno da globalização, pois exprime todas as contradições desse sistema no mundo.

A urbanização seria uma condensação dos processos sociais e espaciais que haviam permitido ao capitalismo se manter e reproduzir suas relações essenciais de produção, e a própria sobrevivência do capitalismo estaria baseada na criação de um espaço social crescentemente abrangente, instrumental e mistificado. É, nesse espaço dialetizado, que se realiza a reprodução das relações de produção, introduzindo nela contradições múltiplas, vindas ou não do tempo histórico (Lefebvre, 2006).

No contexto brasileiro, Queiroz et al. (2016) colocam que o País passou por uma profunda mudança em sua estrutura, a partir da segunda metade do século $X X$, entre as décadas de 1970 e 1980, com o êxodo rural. 0 país deixou de ser essencialmente rural para ser majoritariamente urbano. Esse processo é 
caracterizado por uma das mais rápidas taxas de crescimento urbano de todo o continente americano, sobretudo nos grandes centros urbanos. Atualmente, o percentual da população brasileira vivendo em cidades chega a quase $85 \%$, como uma tendência da dimensão global (IBGE/Pnad, 2016).

No avesso dessa composição, vieram os impasses provocados pelos novos modos de vida de uma sociedade caracterizada pela cultura do consumo individual, cujas marcas estão estreitamente ligadas à lógica da produção capitalista. Segundo essa lógica, as relações de poder tornam-se possíveis pelo acesso a recursos financeiros que delimitam diretamente as relações humanas e geram desigualdades sociais nos diversos espaços.

Cabe salientar que a enorme disparidade econômica existente no País repercute na compreensão de territórios que produzem e reproduzem relações hierárquicas que, muitas vezes, fundamentam-se nas relações de consumo. De acordo com Santos (2004), essas disparidades de renda são menos importantes nos países desenvolvidos e influenciam muito pouco o acesso a um grande número de bens e serviços.

Ao contrário, nos países subdesenvolvidos, a possibilidade de consumo dos indivíduos varia muito. Ou seja, a renda ou o poder econômico acaba por ser um fator determinante na acessibilidade ao consumo, seja ele de bens seja de serviços públicos ou privados. No entanto, a determinante do "[...] nível de renda também é função da localização do indivíduo, o qual determina, por sua vez, a situação de cada um como produtor e consumidor [...]" (ibid., p. 21).

\section{Transporte \\ e metropolização da cidade}

0 crescimento das cidades acarretou uma progressiva demanda por transporte, que tem origem no processo de concentração das atividades cotidianas. Esse fato acarretou uma nova estrutura que aproximou citadinos/as aos equipamentos urbanos, tais como: escolas, hospitais, indústrias, universidades, bancos, ambientes de culto religioso, centro de compras e de lazer, espaços públicos, entre outros. Tudo isso fez do transporte motorizado um instrumento indispensável para concretizar os deslocamentos entre esses equipamentos, mas a oferta por transporte coletivo não cresceu nas mesmas proporções.

De acordo com Bauman (1999), a história moderna foi marcada pelo progresso constante dos meios de transporte. Os transportes e as viagens foram campos de mudança particularmente rápida e radical. No discurso do crescimento econômico e do progresso, a invenção e a produção em massa de meios de transporte inteiramente novos - trens, automóveis e aviões - abriram estradas para a circulação do capital. Para o autor,

[...] a disponibilidade de meios de viagem rápidos desencadeou o processo tipicamente moderno de erosão e solapamento das "totalidades" sociais e culturais localmente arraigadas; foi o processo captado pela primeira vez na famosa fórmula de Tönnies sobre a modernidade como a passagem da Gemeinschaft [comunidade] para a Gesellschaft [associação]. (Ibid., p. 16) 
Nesse contexto, o transporte urbano apresenta-se como uma mercadoria com marcado valor de uso e valor de troca, para satisfazer uma carência, uma necessidade ou um desejo humano, para atender à necessidade de deslocamento de citadinos/as (Harvey, 2013). 0 dinheiro, então, é o recurso utilizado para o seu funcionamento, fazendo desse mecanismo o constructo das relações de poder diretamente ligadas às relações sociais, na medida em que se formam grupos segmentados que correspondem aos diversos meios de transporte (automóveis, ônibus, motocicletas, metrôs e outros).

0 movimento de pessoas tornou-se mais uma exigência social criada pela metropolização do espaço, diante das imposições do mercado de trabalho e em função do próprio mercado precarizado de habitação (Barbosa, 2016, p. 47). Pode-se afirmar que os problemas relacionados à mobilidade em regiões metropolitanas têm influência direta na vida cotidiana da população, podendo ser causadores de redução de qualidade de vida.

Segundo Lefebvre (2006), aquele que possui um espaço na cidade não possui apenas uma unidade habitável; ele adquire uma distância que conecta seu espaço a outras localidades. Isso significa que diferentes classes sociais produzem e, mais importante, consomem o espaço de maneiras diferenciadas, e as relações de conflitos sociais são reproduzidas no espaço urbano.

A concentração de bens, serviços e moradias em áreas determinadas gera um grande volume de deslocamentos pendulares, refletido especialmente nas horas de pico (Bravo et al., 2016). A dimensão desse fato é apresentada nas primeiras pesquisas origem-destino feitas nas metrópoles, em que se constata certo número de municípios periféricos, com grande contingente populacional, nos quais mais de $60 \%$ da força de trabalho se deslocava para outro município para trabalhar. Em São Paulo, no ano de 1977, esse montante chegava a $67 \%$ da força de trabalho de alguns municípios e regiões periféricas intramunicipais, que perfaziam um total de 380 mil trabalhadores (Veloso, 2015, p. 130). No caso de Recife, a pesquisa origem-destino, que está em andamento, divulgou em seu relatório executivo de 2017 que, das pessoas que vivem na RMR e se deslocam pelo sistema metropolitano para irem ao trabalho, $25 \%$ utilizam os terminais integrados (ICPS/Recife, 2017).

De acordo com Harvey (2005), a indústria do transporte, que "vende mudança de localização", é diretamente produtora de valor, pois economicamente considerada a condição espacial, 0 ato de fazer circular as coisas pertence ao próprio processo de produção do capital. Dessa forma, o transporte público coletivo constitui-se como um bem de capital para as empresas privadas que fornecem esses serviços tanto para o uso público quanto privado. Seu valor está ligado à questão do território dos municípios, que recebem uma parcela do lucro decorrente dessa atividade, com base nos requisitos dispostos na Lei de Uso e Ocupação do Solo. ${ }^{1}$ A partir do interesse que lhe é atribuído, o solo assume distintos significados que determinarão o valor de uso e de troca desse espaço.

De acordo com Harvey (2004), o capitalismo tem recorrido repetidas vezes à reorganização geográfica, tanto em termos de expansão quanto de intensificação, como solução parcial para suas crises e seus impasses. Assim, ele constrói e reconstrói uma geografia à sua 
própria imagem e semelhança. Constrói uma paisagem geográfica distintiva, um espaço produzido de transporte e comunicações, de infraestruturas e de organizações territoriais que facilita a acumulação do capital, numa dada fase de sua história, apenas para ter de ser desconstruído e reconfigurado, a fim de abrir caminho para maior acumulação num estágio ulterior.

\section{0 papel do Estado na provisão de equipamentos de transporte urbano}

Para os autores Camara et al. (2017), o transporte, apesar de ser considerado uma atividade-meio do ponto de vista econômico, na atualidade é tido como um influente fator de desenvolvimento regional, mostrando-se um importante eixo para planejamento, desenvolvimento e gestão das cidades. Será que esses aspectos são considerados pelos planejadores urbanos?

Diante da complexidade e contradição das formas de funcionamento das atividades humanas e da produção do espaço, é importante nos questionarmos sobre o papel do Estado na provisão de equipamentos urbanos de transporte (com destaque para aqueles de uso coletivo, utilizados geralmente pela maior parte da população), uma vez que o Estado deve funcionar como mediador na garantia de condições necessárias para o desenvolvimento de uma sociedade em sua totalidade.

A interpretação do papel do Estado no modo de funcionamento das cidades vem de uma concepção histórica vinculada ao processo de formação e organização das sociedades.
Segundo a teoria marxista, o Estado é considerado como

[...] uma forma independente [, que surge da] contradição entre 0 interesse do indivíduo e o da comunidade. [Essa contradição] sempre se baseia [na estrutura social e, em particular,] nas classes, já determinadas pela divisão do trabalho [...] e pela qual uma classe domina todas as outras. (Harvey, 2005, p. 79)

Na citação acima, percebe-se a estreita relação da divisão de classes, delimitadas pela lógica da produção capitalista, por meio da criação de um instrumento para a própria dominação social, cuja representatividade está ligada a interesses particulares dominantes. Tal instrumento envolve certas necessidades sociais, na medida em que facilita mecanismos de acumulação capitalista, garantindo o direito da propriedade privada dos meios de produção, da força de trabalho e de facilidades monetárias, deixando de lado aspectos que são de interesse das camadas subalternas. Como destacam Marx e Engels (1970 apud ibid., p. 84), o Estado capitalista torna-se " [...] a forma de organização que o burguês necessariamente adota para propósitos internos e externos, para a garantia mútua das suas propriedades e dos seus interesses".

Além disso, o Estado precisa mediar certas questões para possibilitar a circulação de mais capital, na medida em que os interesses privados não dispõem de mecanismos para realizá-los isoladamente. Nesse aspecto,

[...] o Estado também deve desempenhar um papel importante no provimento de "bens públicos" e infraestruturas sociais e físicas; pré-requisitos necessários para a produção e troca capitalista, mas os quais 
nenhum capitalista individual acharia possível prover com lucro. (Ibid., p. 85)

Merece destaque o papel de mediador do Estado nas relações de produção capitalista, o que descarta a característica de neutralidade, um tanto mascarada pelos interesses privados de regulação e dominação social, uma vez que não se trata de um objeto, mas de um conjunto de representações institucionais com interesses privados. Conforme ressalta Vainer (2009, p. 87), " [...] a parceria público-privada assegurará que os sinais e interesses do mercado estarão adequadamente presentes, representados, no processo de planejamento e decisão".

Tendo a cidade como suporte para efetivação desse modo de funcionamento, é inevitável relacionar as condições de provisão dos equipamentos urbanos à lógica da produção capitalista, de modo que o transporte se torna uma mercadoria de interesse para a acumulação do capital e com grande potencial competitivo. Isto se dá na medida em que o Estado amplia a sua comercialização, em termos internacionais, importa novas tecnologias e faz girar mais produtos que garantem prestígio e status ao consumidor. Dessa forma, configura-se uma complexidade que transita num espaço de fluxos, definido por Castells (1999) como uma organização material das práticas sociais de tempo compartilhado que funcionam por meio de fluxos.

Quanto aos transportes de uso coletivo, como eles funcionam, sob a lógica de produção capitalista? A realidade é que operam acima das suas condições de funcionamento, sobrecarregados, com tecnologias obsoletas, remendados e inseridos em um contexto que não lhes permite funcionar corretamente. Eles estão de acordo com a prática de um Estado Neoliberal, cuja prioridade é o lucro em detrimento da qualidade de vida dos usuários/as do serviço de transporte, numa lógica de alienação e segmentação de classe. De acordo com Harvey (2008, p. 86),

[...] à medida que o Estado reduz os recursos dedicados ao bem-estar social e reduz o seu papel em áreas como a assistência à saúde, o ensino público e a assistência social, que um dia foram tão fundamentais para o liberalismo embutido, o Estado vai deixando segmentos sempre crescentes da população expostos ao empobrecimento.

Em consequência, o Estado reduz investimentos para um serviço de "caráter essencial", que é executado por empresas terceirizadas, fazendo de um instrumento tão necessário ao deslocamento urbano algo desgastante, física e emocionalmente, para quem o utiliza cotidianamente. $A$ despeito de que o transporte está inserido como um direito social, ${ }^{2}$ que precisa ser garantido pelo Estado brasileiro a todo e qualquer cidadão nesse território, efetivamente não se observam avanços, e os usuários/as são submetidos a viajarem cada vez mais "enlatados" dentro dos veículos.

\section{Os arranjos institucionais na gestão do transporte urbano metropolitano}

0 intenso processo de urbanização no Brasil gerou o fenômeno da metropolização, ocupação urbana que ultrapassa os limites das 
cidades e, consequentemente, o desenvolvimento de grandes aglomerações metropolitanas. Ao longo do processo de provisão de serviços públicos no País, sobretudo a partir da década 1960, ocorreu a discriminação progressiva de estruturas especializadas em cada área de atuação governamental, dentre as quais a educação, a saúde, a habitação e os transportes (Farah, 2001, p. 122). Desse modo, abre-se margem para uma dinâmica de setorialidade das funções e atribuiç̧ão dos serviços prestados.

Para Arretche (1996), o grande consenso em torno da descentralização produziu-se a partir de perspectivas políticas distintas, supondo-se que formas descentralizadas de prestação de serviços públicos seriam mais eficientes e que, portanto, elevariam os níveis reais de bem-estar da população. De acordo com Farah (ibid., p. 127), a descentralização consiste em um processo de "[...] substituição do modelo de provisão estatal por um modelo em que o Estado deixa de ser o provedor direto exclusivo e passa a ser o coordenador e fiscalizador de serviços que podem ser prestados pela sociedade civil ou pelo mercado ou em parceria com esses setores". Quando a descentralização ocorre no âmbito de empresas, ou entre empresas e setor público, verifica-se um processo de terceirização (Melo, 1996). Segundo Mattos (2007, p. 90),

[...] la descentralización ha permitido que las administraciones locales dispongan de facultades más amplias para negociar directamente con los capitales privados las condiciones requeridas por estos para aumentar alli sus inversiones.

Apesar de a Constituição Federal de 1988 ter enfatizado a descentralização fiscal, a municipalização de políticas públicas foi se consolidando apenas ao longo dos anos 1990, assumindo variados ritmos, dependendo da área (Abrucio e Franzese, 2007). Se, por um lado, a constituição dessas estruturas resultou do reconhecimento da crescente complexidade da problemática social no País, a exigir respostas que considerassem a singularidade dos desafios de cada uma das áreas sociais, por outro, essa especialização acabou se traduzindo em autonomia.

Segundo Farah (2001, p. 122),

[...] cada política social e cada setor de serviço público estão sendo concebidos de forma independente dos demais, sem uma articulação entre as ações das diferentes áreas. Disto decorria não apenas a perda de potenciais efeitos positivos de ações coordenadas dirigidas a um mesmo público-alvo, mas também o comprometimento de determinadas políticas, pela inexistência de serviços complementares de outro setor.

Isto se dá, mesmo partindo do conceito de Federação, que é vista como uma " [...] forma de organização político-territorial baseada no compartilhamento tanto da legitimidade como das decisões coletivas entre mais de um nível de governo" (Abrucio e Franzese, 2007, pp. 1-2).

Muitas vezes, a coordenação regional intraestadual tem ficado por conta dos próprios municípios, que se articulam em torno de uma questão por meio da formação de consórcios intermunicipais. "Os consórcios formalizam a cooperação intermunicipal com o objetivo de reunir esforços em torno de um problema cuja solução extrapola os limites de um município e atinge a dimensão microrregional ou regional" 
(ibid., pp. 14-15). 0 resultado dessa cooperação pode ser a realização de obras, serviços ou até mesmo planejamento conjuntos.

No Brasil, as Parcerias Público-Privadas (PPPs) surgem como uma "[...] modalidade de contratação em que os entes públicos e as organizações privadas, mediante o compartilhamento de riscos e com financiamento obtido pelo setor privado, assumem a realização de serviços e empreendimentos públicos" (Lima, Paula e Paula, 2005, p. 113). No caso britânico, a implementação do programa Private Finance Initiative, estratégia semelhante às PPPs no Brasil, tem sido utilizada em 20 setores diferentes da economia do Reino Unido. No entanto, quem mais utiliza esse esquema tem sido o Ministério de Transportes, responsável por $22 \%$ dos projetos em termos de valor capital (Peci e Sobral, 2007, p. 4). Tal estratégia segue a lógica de transferência de riscos financeiros para o setor privado, sob a perspectiva do institucionalismo de escolha racional, como instrumento norteador de gestão e eficiência (Hall e Taylor, 2003).

\section{As políticas urbanas de transporte no Brasil: avanços e entraves}

Segundo o Instituto de Pesquisa Econômica Aplicada - Ipea (2016), os sistemas de mobilidade urbana no Brasil têm passado por diversas mudanças nos últimos sessenta anos, com o aumento da taxa de motorização da população e o crescimento acelerado dos grandes centros urbanos. 0 nascimento da indústria automotiva no País, em meados do século XX, associado à dispersão dos locais de estudo e trabalho, observada nos últimos anos, impulsionaram a forte urbanização brasileira, que se deu segundo os princípios do transporte motorizado rodoviário. Desde então, o ônibus tem se mantido como o meio de transporte coletivo mais utilizado nas cidades brasileiras (ibid.).

A particularidade da cidade, enquanto fenômeno a ser juridicamente regulado, deu origem ao direito urbanístico, ramo do direito dedicado às relações que envolvem a construção, a conservação e o uso dos espaços urbanos públicos e privados. São objetos do direito urbanístico, por exemplo, o parcelamento do solo, o zoneamento e as obras públicas. No contexto da globalização, os direitos humanos consolidaram-se como um tema global, cujo processo tem como marco a universalização dos direitos, com base na Declaração Universal dos Direitos Humanos de 1948, estabelecida pelas Nações Unidas. De acordo com Saule Júnior (1997, p. 65), desse período até 1988, a trajetória dos direitos humanos foi marcada por diversas convenções e declarações internacionais que estabeleceram organismos e mecanismos de proteção desses direitos. Daí em diante, o indivíduo passou a ser considerado sujeito de direito, não apenas no âmbito do Estado no qual é cidadão, mas um sujeito de direito internacional.

No Brasil, as políticas relacionadas ao direito aos transportes surgiram a partir da promulgação da Constituição Federal, em 1988. No capítulo II, artigo $7^{\circ}$, inciso IV da Carta Magna, o transporte aparece enquanto direito dos trabalhadores urbanos e rurais, assim como o direito ao salário mínimo, a fim de promover a melhoria das condições sociais dos trabalhadores. A prestação do serviço nos 
limites de Estado, território e nível internacional é de competência da União. 0 direito aos transportes está vinculado às diretrizes do desenvolvimento urbano junto à política nacional de transportes, e compete, aos municípios a prestação dos serviços públicos de transporte coletivo, denominados de caráter essencial.

Após esse período, houve a necessidade de regular os modos de circulação dos equipamentos e agentes do transporte nacional, quando surgiu o Código de Trânsito Brasileiro em 1997. 0 artigo $1^{\circ}$, parágrafo $2^{\circ}$ da lei n. 9.503/1997, define que o trânsito, em condições seguras, é um direito de todos e dever dos órgãos e entidades componentes do Sistema Nacional de Trânsito, cabendo-Ihes, no âmbito das respectivas competências, adotar as medidas destinadas a assegurar esse direito (Brasil, 1997).

Em 2001, foi promulgado o Estatuto da Cidade (lei n. 10.257) como um instrumento de política pública que estabelece, entre algumas das suas diretrizes gerais, a garantia de transporte público urbano ao cidadão. Define, ainda, que são atribuições da União instituir as diretrizes para desenvolvimento urbano, inclusive transporte e mobilidade urbana. Adicionalmente, exige que cidades com mais de 500 mil habitantes devem elaborar um Plano de Transporte Urbano Integrado (ibid., 2001).

Só depois de 10 anos, em janeiro de 2012, foi instituída a Política Nacional de Mobilidade Urbana, objetivando o acesso universal à cidade, a partir da integração entre os diferentes modos de transporte, por meio do Sistema Nacional de Mobilidade Urbana, visando à melhoria da acessibilidade e mobilidade das pessoas e cargas no território nacional (ibid., 2012).
Pouco depois, foi promulgado o Estatuto da Metrópole (2015), que estabelece diretrizes para o planejamento, a gestão e a execução das funções públicas de interesse comum cuja realização por um município, isoladamente, cause impacto em municípios limítrofes de regiões metropolitanas e em aglomerações urbanas. Destaca, como diretrizes mais relevantes, a implantação de processo compartilhado de planejamento, a tomada de decisão e a administração e execução de funções públicas de interesse comum, organizados em consórcios multifederativos, prática crescente na rede de transportes metropolitanos. Exige, ainda, a compatibilização dos planos plurianuais, das leis de diretrizes orçamentárias e dos orçamentos anuais dos entes envolvidos na governança. Define, também, que as regiões metropolitanas deverão contar com um plano de desenvolvimento urbano integrado. Porém, a elaboração desse plano não exime os municípios integrantes da região metropolitana da formulação de seus respectivos Planos Diretores, que deverão ser compatibilizados com o Plano de Desenvolvimento Urbano Integrado (ibid., 2015).

0 avanço mais recente relacionado às políticas de transporte no Brasil foi com sua inserção no âmbito do direito social, que se coloca no mesmo patamar que o direito à saúde, à educação, à alimentação e à moradia (ibid.). No Quadro 1, estão listados os marcos legais referentes às políticas de transporte no Brasil.

Para a autora da Proposta de Emenda à Constituição, que permitiu a mudança na redação do texto (PEC 90/2011), deputada Luiza Erundina, a definição do transporte como um direito social, pela Constituição Federal, obriga o Estado a garantir esse serviço a todos os cidadãos brasileiros. Segundo a deputada, 
Quadro 1 - Instrumentos da Política Nacional sobre Transportes Urbanos

\begin{tabular}{|l|l|c|}
\hline \multicolumn{1}{|c|}{ Política } & \multicolumn{1}{c|}{ Marco legal } & \multicolumn{1}{c|}{ Data } \\
\hline Política de Desenvolvimento Urbano & Constituição Federal & 1988 \\
Código de Trânsito Brasileiro & Lei $\mathrm{n}^{\circ} 9.503$ & 23 de setembro de 1997 \\
Estatuto da Cidade & Lei $\mathrm{n}^{\circ} 10.257$ & 10 de julho de 2001 \\
Política Nacional de Mobilidade Urbana & Lei $\mathrm{n}^{\circ} 12.587$ & 3 de janeiro de 2012 \\
Estatuto da Metrópole & Lei $\mathrm{n}^{\circ} 13.089$ & 12 de janeiro de 2015 \\
Introduz o transporte como direito social & Emenda Constitucional $\mathrm{n}^{\circ}$ 90 & 15 de setembro de 2015 \\
\hline
\end{tabular}

Fonte: Instrumentos legais brasileiros.

isso significa uma conquista importante, sobretudo para aqueles que dependem do transporte coletivo para ter acesso aos outros direitos sociais.

Para o diretor da Associação Nacional das Empresas de Transportes Urbanos - NTU (2015), a PEC 90/2011 veio somar-se à lei federal 12.587/2012, mais conhecida como Lei da Mobilidade Urbana, que traz instrumentos fundamentais para garantir a sustentabilidade e a eficiência nos deslocamentos.

No entanto, os avanços se dão a passos lentos, apesar da constatação de diversos projetos relacionados à mobilidade urbana em execução no País, como corredores e faixas exclusivas de metrô, ônibus, $\mathrm{BRT}^{3}{ }^{3}$ etc. 0 tempo de execução excede o período previsto, e o que se percebe são obras não concluídas e serviços funcionando fora dos prazos estabelecidos.

\section{O serviço de ônibus na Região Metropolitana do Recife}

Quem precisa realizar suas atividades cotidianas e utiliza o ônibus como principal meio de transporte na Região Metropolitana do Recife, sente-se como um enlatado no trânsito urbano, desgastado pela falta de acessibilidade aos equipamentos, sem conforto nem segurança. $A$ Figura 1 registra a rotina de quem usa o serviço de ônibus na região.

Depender desses instrumentos é comprometer boa parte do tempo que poderia ser empregado para outras finalidades. São ônibus superlotados, atrasados, sem previsão de chegada, extensas filas de espera, correria, apertos, empurrões, assédios, desrespeito... Um constante esgotamento físico e mental, marcado 
Figura 1 - O cotidiano de usuários/as do serviço de ônibus na RMR

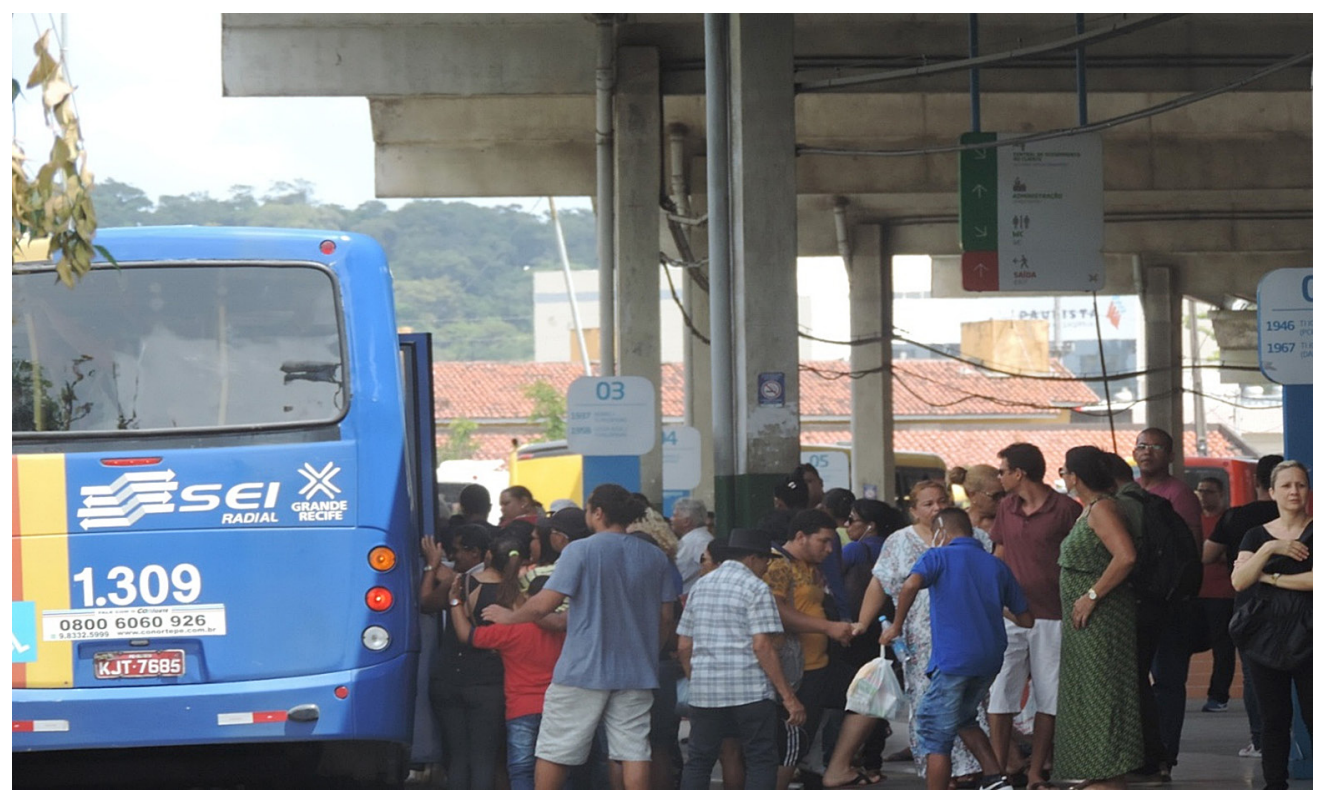

Fonte: autores, 2018.

pelo cansaço provocado pelo desgaste intenso, que interfere na qualidade de vida das pessoas e de suas famílias.

A Região Metropolitana do Recife (RMR) foi instituída em 1973, pela lei complementar estadual n. 14/73. Foi uma das primeiras regiões metropolitanas constituídas no Brasil (Observatório das Metrópoles, 2010). Em 1987, o Instituto Brasileiro de Geografia e Estatística (IBGE) reconheceu a RMR como metrópole regional, ressaltando a importância política e econômica por ela exercida. Atualmente, a região caracteriza-se como o segundo maior aglomerado urbano do Nordeste e o sexto do Brasil. A Figura 2 ilustra a RMR com os seus municípios.
Para Ferraz e Torres (2004), a facilidade de deslocamento das pessoas, que dependem das características do sistema de transporte de passageiros, é um fator importante na caracterização da qualidade de vida de uma sociedade e, por consequência, do seu grau de desenvolvimento econômico e social. Segundo Vasconcellos (2006), um modelo adequado do sistema de transporte coletivo contribui com uma significativa melhoria na qualidade de vida de seus cidadãos.

Na RMR, o sistema de transporte público coletivo é gerido por meio de um consórcio, que funciona como instrumento de gestão de uma política pública estratégica, com um arranjo institucional de governança metropolitana 
Figura 2 - Mapa da Região Metropolitana do Recife

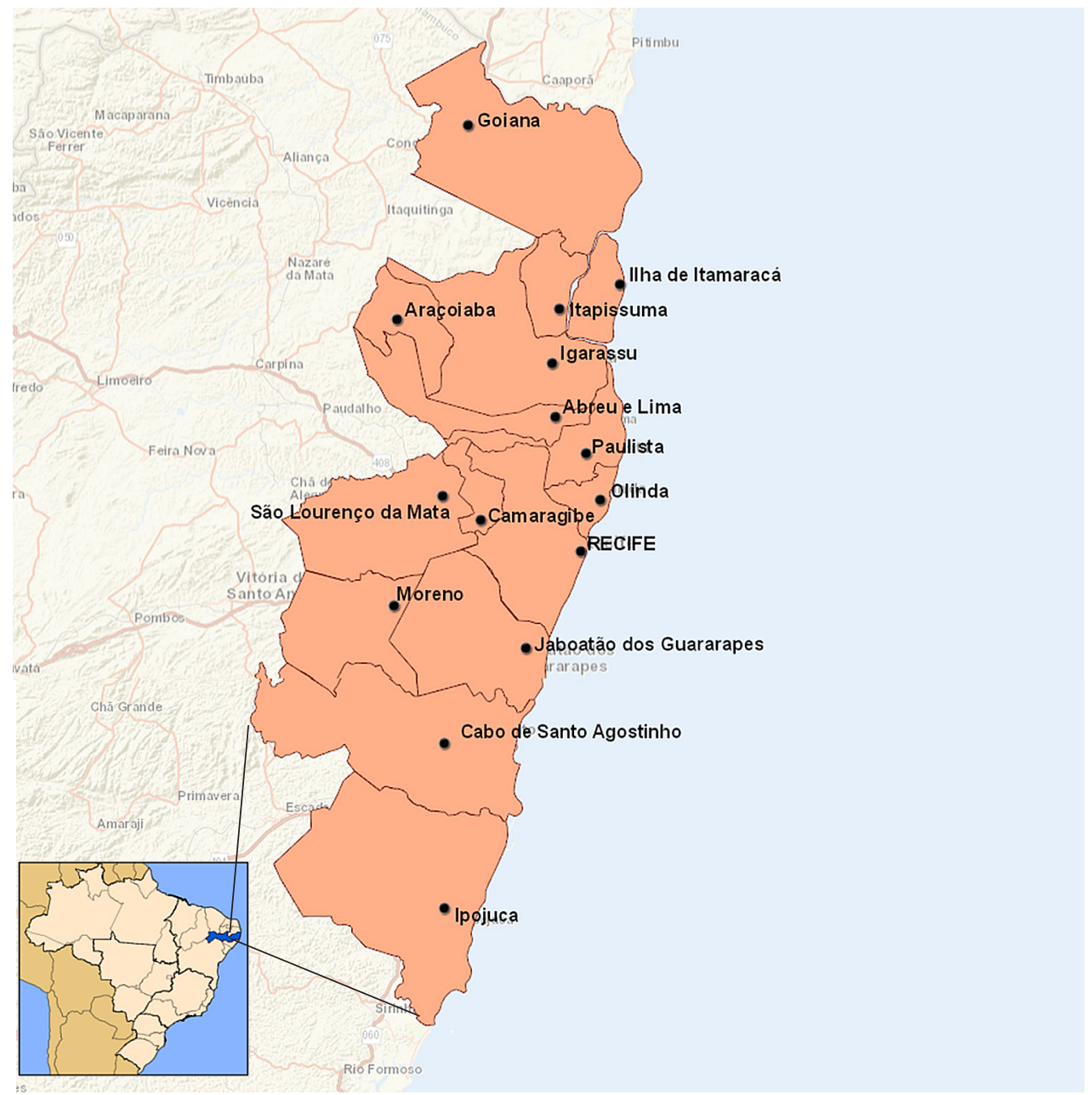

Fonte: autores, 2018. Adaptado do Esri - ArcGIS.

(Best, 2011). 0 Grande Recife Consórcio de Transporte Metropolitano é a primeira instituição intergovernamental de âmbito metropolitano estabelecida no País. Foi criado em 2008 para substituir a Empresa Metropolitana de Transportes Urbanos (EMTU/Recife), que é a experiência mais antiga de gestão metropolitana de transportes públicos de passageiros no
Brasil e que se manteve em funcionamento até 0 ano de 2008 (Ramalho, 2009, p. 110).

No caso do Grande Recife, o princípio básico da criação do Consórcio é a gestão associada do Sistema de Transporte Público de Passageiros/RMR, considerado fundamental para assegurar a eficiência e a qualidade na prestação dos serviços públicos de transportes, 
na RMR. Entre suas principais funções, o Consórcio de Transporte Metropolitano (Figura 3) é responsável por planejar e gerir o sistema de transporte público coletivo da região metropolitana (Best, 2011).

Dentre suas principais missões estão: contratar os serviços de transportes por meio de licitações públicas; planejar e gerir o STTP/ RM do Recife, assegurando a qualidade e a universalidade dos serviços; fiscalizar e atualizar os contratos de concessão; e regulamentar as atividades concedidas (Ipea, 2015).

Segundo Ramalho (2009), o Grande Recife Consórcio de Transporte Metropolitano constitui entidade multifederativa e empresa pública dotada de personalidade jurídica de direto privado, sem fins lucrativos, com sede e foro na cidade do Recife. Quanto aos recursos financeiros, são decorrentes das:
[...] vendas de bilhetes, quotas de contribuição dos sócios do CTM estabelecidas através do Contrato de Rateio, da renda dos bens patrimoniais, doações, de fundos de transportes e de outras fontes. (Ibid., p. 126)

Para Borges e Delgado (2011), a experiência do consórcio do Recife mostra vantagens proporcionadas pelo arranjo institucional na integração tarifária, nas concessões às empresas, no planejamento das rotas, na mediação e solução de conflitos entre os entes federados, na regulação e qualidade e na hierarquização da rede. São avanços que já garantem uma mudança no serviço aos usuários e mostram reflexos espaciais na região, mediante a desconcentração dos serviços. Não obstante, uma das maiores vantagens que o consórcio proporciona não foi bem-aproveitada no Recife, que é

Figura 3 - Modelo Institucional de Gestão do Serviço de Ônibus na RMR

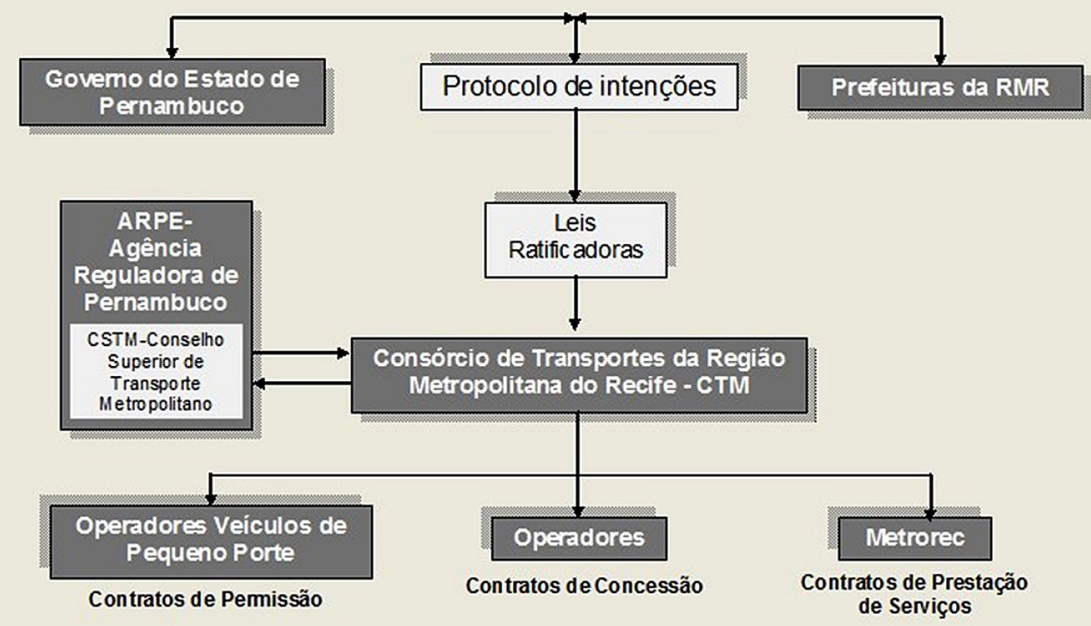

Fonte: EMTU (2007, apud Ramalho, 2009). 
a integração entre o planejamento urbano e o de transportes.

0 que se vê são usuários/as insatisfeitos/ as, desgastados/as, exaustos/as antes mesmo de chegarem aos seus destinos para realizar suas tarefas e, quando chegam em casa, só desejam descansar para se levantarem no outro dia. 0 sistema de integração entre as linhas desempenha mais uma função de gargalo no fluxo das viagens, por onde os usuários/as são obrigados/as a interromper suas viagens para fazerem as transferências de um coletivo a outro.

As condições atuais mostram que é preciso avançar na qualidade dos serviços. Construir novas formas de lutar por melhores condições de circulação nos espaços urbanos é um desafio constante, e o transporte abarca um conjunto dessas variantes. Desse modo, o direito à cidade é muito mais do que um direito de acesso individual ou grupal aos recursos que a cidade oferece. É o direito de mudar e reinventar a cidade, de acordo com nossos mais profundos desejos. Além disso, é um direito mais coletivo do que individual, uma vez que reinventar a cidade depende inevitavelmente do exercício de uma prática coletiva sobre o processo de urbanização (Harvey, 2014, p. 28).

De acordo com Silva e Bowns (2008), a mobilidade é um importante indicador de qualidade de vida, pois mover-se na cidade é um requisito básico ao desenvolvimento da maioria das atividades humanas, sendo estas de lazer, trabalho, estudo ou comércio. Assim, a mobilidade espacial está diretamente relacionada à inclusão social.

Enquanto alguns podem escolher seus padrões de desenvolvimento livremente, grande parte da população urbana vive em condições restritivas e ineficientes de mobilidade, uma condição perpetuada pela concentração de investimentos em estruturas que privilegiam o deslocamento de carros ao invés do transporte público (Roure, 2001).

Segundo Santos (2006), o endurecimento da cidade é paralelo à ampliação da intencionalidade na produção dos lugares, atribuindo-lhes valores específicos e mais preciosos, diante dos usos preestabelecidos. Esses lugares, que transmitem valor às atividades que aí se localizam, dão margem a uma nova modalidade de criação e escassez e a uma nova segregação. "Esse é o resultado final do exercício combinado da ciência e da técnica do capital e do poder, na reprodução da cidade" (ibid., p. 169).

\section{Considerações finais}

As condições atuais de mobilidade nas cidades apresentam-se como um fenômeno experienciado pela sociedade urbana, com dilemas que problematizam os modos de circular das pessoas, vinculados em uma dinâmica de mercado da produção e das relações de consumo no espaço.

0 arranjo urbano foi adquirindo novos formatos, e os fluxos das atividades humanas se intensificaram. A necessidade de deslocamento fez do transporte um instrumento indispensável no cotidiano de citadinos/as e, no contexto nacional, se transformou em um direito social de cidadãos/as. Apesar de ser responsabilidade do poder público, o Estado assume uma posição secundária na prestação do serviço de transporte público coletivo, entregando ao mercado os instrumentos para a realização dessa atividade. 
No caso da Região Metropolitana do Recife, o serviço é executado por meio de um consórcio que integra instrumentos de planejamento, gestão e execução das atividades vinculadas ao Sistema de Transporte Público de Passageiros. Apesar de representar uma experiência pioneira no setor, ainda apresenta limitações em sua própria estrutura que se reflete, por sua vez, diretamente na qualidade do serviço prestado aos usuários/as.

Se a necessidade de deslocamento é tida como uma mercadoria, ela seguirá as tendências da lógica de segregação de classe, em que o acesso ao lugar será avaliado em função dos recursos econômicos. 0 direito ao transporte tem o seu preço, assim como as horas despendidas nele. Quem pagará por esse tempo? Nessa relação parece que espaço e tempo podem ser calculados, mas, na realidade, eles não têm valor de troca; é o tempo cronológico, não remunerado, imposto e improdutivo. Tempo que deixa de ser experienciado e passa a ser consumido e descartado continuamente.

Na dinâmica de produção dos lugares, 0 transporte reúne as expressivas espacialidades da distribuição dos arranjos sociais na cidade. 0 indivíduo torna-se mercadoria ambulante que se move sobre os espaços demarcados. 0 transporte, sobretudo, público coletivo desloca a massa de operários do mercado, sejam eles da produção ou do consumo no sistema capitalista. As cidades sobre rodas movem-se em direção do núcleo, para produzirem valor, e se distanciam para reproduzirem, nas áreas periféricas, a mão de obra para essa informalidade.

É necessário colocar no centro dos debates sobre produção da cidade o "sentir-se" usuário/a de ônibus. Pensar a cidade é voltar-se para as pessoas e ver através da perspectiva delas, reconhecendo-as enquanto sujeitos desse processo. Do contrário, a cidade infla instantaneamente e continua a reproduzir a sua não identidade.

\section{[I] https://orcid.org/0000-0002-8435-613X}

Universidade Federal de Pernambuco, Departamento de Arquitetura e Urbanismo, Programa de Pós-Graduação em Desenvolvimento Urbano. Recife, PE/Brasil.

mariliadonascimentosilva@hotmail.com

\section{[II] https://orcid.org/0000-0003-1763-1004}

Universidade Federal de Pernambuco, Departamento de Arquitetura e Urbanismo, Programa de Pós-Graduação em Desenvolvimento Urbano. Recife, PE/Brasil. thlapa@hotmail.com 


\section{Notas}

(1) Trata-se se de um instrumento municipal de planejamento territorial que permite caracterizar zonas da cidade com funções específicas, de modo a disciplinar as atividades da iniciativa no território urbano de modo equilibrado entre as demandas sociais e o desenvolvimento econômico. A Lei de Uso e Ocupação do Solo impacta diretamente nos padrões de deslocamento diário da população (Duarte, Sánchez e Libardi, 2012, p. 13).

(2) Art. 6. Constituição Federal, 1988. Emenda constitucional n. 90, de 15 de setembro de 2015.

(3) O termo Bus Rapid Transit (BRT) foi adotado nos anos 1990 na América do Norte, porém, a associação das palavras Rapid Transit (Transporte Rápido) com os custos da tecnologia de ônibus implícitos no termo Bus criou uma referência e uma imagem mundial que substituíram os termos mais antigos como express buses, busways ou até Bus à Haut Niveau de Service (BHNS) na França.

\section{Referências}

ABRAMO, P. (1995). A regulação urbana e o regime urbano: a estrutura urbana, sua reprodutibilidade e o capital. Ensaios da Fundação de Economia e Estatística. Porto Alegre, v. 16, n. 2, pp. 510-555.

ABRUCIO, F. e FRANZESE, C. (2007). "Federalismo e políticas públicas: o impacto das relações intergovernamentais no Brasil”. In: ARAÚJO, M. e BEIRA, L. (orgs.). Tópicos da economia paulista para gestores públicos. São Paulo, Fundap.

ARRETCHE, M. (1996). Mitos da descentralização: mais democracia e eficiência nas políticas públicas? Revista Brasileira de Ciências Sociais. São Paulo, v. 11, n. 31, pp. 44-66.

AUGÉ, M. (2010). Por uma antropologia da mobilidade. Maceió, Edufal/Unesp.

BARBOSA, J. (2016). "O significado da mobilidade na construção democrática da cidade". In: IPEA. Cidade e movimento: mobilidade e interações no desenvolvimento urbano. Brasília, Instituto de Políticas de Transporte e Desenvolvimento/ITDP.

BAUMAN, Z. (1999). Globalização: as consequências humanas. Rio de Janeiro, Jorge Zahar.

BEST, N. (2011). A experiência do Grande Recife Consórcio de Transporte Metropolitano. Cadernos ADENAUER XII, n. 4, pp. 179-202.

BORGES, I. e DELGADO, J. (2011). A importância da gestão compartilhada nos consórcios públicos para a gestão dos sistemas de transporte nas regiões metropolitanas. In: SEMINÁRIO URBANISMO NA BAHIA - DIREITO À CIDADE, CIDADE DO DIREITO, 11. Anais... Salvador, UFBA, pp. 1-20.

BRASIL (1997). Lei Federal no 9.503, de 23 de setembro. Institui o Código de Trânsito Brasileiro. Diário Oficial da República Federativa do Brasil. Disponível em: http://www.planalto.gov.br/Ccivil_03/ leis/L9503.htm. Acesso em: jan 2018. 
BRASIL (2001). Lei Federal no 10.257, de 10 de julho. Estatuto da Cidade. Diário Oficial da República Federativa do Brasil. Disponível em: http://www.planalto.gov.br/Ccivil_03/leis/LEIS_2001/ L10257.htm. Acesso em: dez 2017.

(2012). Lei Federal no 12.587, de 3 de janeiro. Institui as diretrizes da Política Nacional de Mobilidade Urbana. Diário Oficial da República Federativa do Brasil, 4 jan 2012. Disponível em: http://www2.camara.leg.br/legin/fed/lei/2012/ lei-12587-3-janeiro-2012-612248publicacaooriginal-134894-pl.html. Acesso em: jan 2017.

(2015). Lei Federal no 13.089, de 12 de janeiro de 2015: Estatuto da Metrópole. Diário Oficial da República Federativa do Brasil. Disponível em: http://www.planalto.gov.br/ccivil_03/_ato20152018/2015/lei/I13089.htm. Acesso em: jan 2018.

(2015). Emenda constitucional no 90, de 15 de setembro de 2015. Dá nova redação ao art. 6ㅇda Constituição Federal, para introduzir o transporte como direito social. Diário Oficial da República Federativa do Brasil. Disponível em: http://www2.camar a.leg.br/legin/fed/emecon/2015/ emendaconstitucional-90-15-setembro-2015-781520 publicacaooriginal-148098-pl.html. Acesso em: jan 2017.

BRAVO, M. et al. (2016). Estudos para implantação de estações de BRT na Região Metropolitana de Florianópolis: o uso do sistema de Informação Geográfica (SIG) como ferramenta de análise. In: CONGRESSO NACIONAL DE PESQUISA EM TRANSPORTE DA ANPET, 30. Anais... Rio de Janeiro, ANPET, pp. 2099-2110.

CAMARA, M. et al. (2017). Estudo de tempos de viagem motivo casa-trabalho no município do Rio de Janeiro. In: CONGRESSO NACIONAL DE PESQUISA EM TRANSPORTE DA ANPET, 31. Anais... Recife, ANPET, pp. 2535-2546.

CASTELLS, M. (1999). "O espaço de fluxos”. In: CASTELLS, M. A sociedade em rede. São Paulo, Paz e Terra.

DUARTE, F.; SÁNCHEZ, K. e LIBARDI, R. (2012). Introdução à mobilidade urbana. Curitiba, Juruá.

FARAH, M. (2001). Parcerias, novos arranjos institucionais e políticas públicas no nível local de governo. Revista de Administração Pública. Rio de Janeiro, v. 35, n. 1, pp. 119-144.

FERRAZ, A. e TORRES, I. (2004). Transporte público urbano. São Paulo, Rima.

HALL, P. e TAYLOR, R. (2003). As três versões do neo-institucionalismo. Lua Nova Revista de Cultura e Política. São Paulo, v. 58, n. 1, pp.193-223.

HARVEY, D. (2004). Espaços de esperança. São Paulo, Loyola.

(2005). A produção capitalista do espaço. São Paulo, Annablume.

(2008). "O Estado neoliberal”. In: HARVEY, D. O neoliberalismo: história e implicações. São Paulo, Loyola.

(2013). “A mercadoria”. In: HARVEY, D. Para entender O capital. São Paulo, Boitempo.

(2014). "O direito à cidade". In: HARVEY, D. Cidades rebeldes: do direito à cidade à revolução urbana. São Paulo, Martins Fontes.

IBGE (2016). Pesquisa nacional por amostra de domicílios: síntese de indicadores 2015. Rio de Janeiro, IBGE. 
ICPS - INSTITUTO DA CIDADE PELÓPIDAS SILVEIRA. (2017). Pesquisa origem-destino do Recife: relatório executivo. Recife, ICPS.

IPEA (2015). Governança metropolitana no Brasil. Rio de Janeiro.

(2016). Cidade e movimento: mobilidades e interações no desenvolvimento urbano. Brasília, Ipea.

LEFEBVRE, H. (1999). "Da cidade à sociedade urbana”. In: LEFEBVRE, H. A revolução urbana. Belo Horizonte, UFMG.

(2006). A produção do espaço. Disponível em: https://gpect.files.wordpress.com/2014/06/ henri_lefebvre-aproduc3a7c3a3o-do-espac3a7o.pdf. Acesso em: mar 2018.

LIMA, J.; PAULA, L. e PAULA, R. (2005). Entendendo a parceria público privada no Brasil: uma análise preliminar. Revista do Tribunal de Contas. Recife, v. 16, n. 6, pp. 103-126.

MATTOS, C. (2007). Globalización, negocios inmobiliarios y transformación urbana. Nueva Sociedad. Buenos Aires, v. 212, n. 1, pp. 82-96.

MELO, M. A. (1996). Crise federativa, guerra fiscal e "hobbesianismo municipal": efeitos perversos da descentralização? São Paulo em Perspectiva. São Paulo, v. 10, n. 3, pp. 11-20.

OBSERVATÓRIO DAS METRÓPOLES (2010). Regiões Metropolitanas do Brasil. Rio de Janeiro, Ippur. Disponível em: http://www.observatoriodasmetropoles.net/download/ observatorio_RMs2010. pdf. Acesso em: out 2017.

PECI, A. e SOBRAL, F. (2007). Parcerias público-privadas: análise comparativa das experiências britânica e brasileira. Cadernos EBAPE. Rio de Janeiro, v. 5, n. 2, pp. 1-14.

QUEIROZ, R. C. et al. (2016). Análise do transporte coletivo rodoviário: comparativo de custo e do nível de serviço do BRT com o sistema convencional. In: CONGRESSO NACIONAL DE PESQUISA EM TRANSPORTE DA ANPET, 30. Anais... Rio de Janeiro, ANPET, pp. 1108-1119.

RAMALHO, A. M. (2009). Autonomia e cooperação: os desafios da gestão metropolitana. Tese de Doutorado. Recife, Universidade Federal de Pernambuco.

ROURE, G. (2001). Família, subjetividade e espaço urbano. Revista do Laboratório de Estudos Urbanos do Núcleo de Desenvolvimento da Criatividade. Campinas, v. 17, n. 1, pp. 127-140.

SANTOS, M. (2004). Por uma outra globalização: do pensamento único à consciência universal. Rio de Janeiro, Record.

(2006). A natureza do espaço: técnica e tempo, razão e emoção. São Paulo, Edusp.

SAULE JÚNIOR, N. (1997). O direito à moradia como responsabilidade do Estado Brasileiro. Cadernos de Pesquisa. São Paulo, n. 7, pp. 65-80.

SECCHI, B. (2006). Primeira lição de urbanismo. São Paulo, Perspectiva.

SILVA, C. e BOWNS, C. (2008). Transporte e equidade: ampliando o conceito de sustentabilidade pelo estudo de caso de Brasília. Revista Cadernos Metrópole. São Paulo, v. 10, n. 19, pp. 293-317.

VAINER, C. (2009). Pátria, empresa e mercadoria: Notas sobre a estratégia discursiva do Planejamento Estratégico Urbano. In: ARANTES, O.; VAINER, C. e MARICATO, E. A cidade do pensamento único: desmanchando consensos. Petrópolis, Vozes. 
VASCONCELLOS, E. (2006). Transporte e meio ambiente: conceitos e informações para análise de impactos. São Paulo, Annablume.

VELOSO, A. H. (2015). O ônibus, a cidade e a luta: a trajetória capitalista do transporte urbano e as mobilizações populares na produção do espaço. Dissertação de Mestrado. Belo Horizonte, Universidade Federal de Minas Gerais.

Texto recebido em 30/maio/2018

Texto aprovado em 16/set/2018 